Article

\title{
Digital Literacy Key Performance Indicators for Sustainable Development
}

\author{
Danica Radovanović ${ }^{1, *}$, Christine Holst ${ }^{2}$, Sarbani Banerjee Belur ${ }^{3,4}$, Ritu Srivastava ${ }^{4}$, \\ Georges Vivien Houngbonon ${ }^{5}$, Erwan Le Quentrec ${ }^{5}$, Josephine Miliza ${ }^{6}$, Andrea S. Winkler ${ }^{7}$ and Josef Noll ${ }^{8}$ \\ ${ }^{1}$ Basic Internet Foundation, 2007 Kjeller, Norway; E-Mail: danica@basicinternet.org \\ ${ }^{2}$ Centre for Global Health, Department of Community Medicine and Global Health, Institute of Health and Society, \\ University of Oslo, 0318 Oslo, Norway; E-Mail: christine.holst@medisin.uio.no \\ ${ }^{3}$ Gram Marg, 400076 Mumbai, India; E-Mail: sarbanibelur@iitb.ac.in \\ ${ }^{4}$ Spoken Tutorial Health and Nutrition Project, Indian Institute of Technology Bombay, 400076 Mumbai, India; \\ E-Mail: ritu.instablogs@gmail.com \\ 5 Orange Labs, 92320 Châtillon, France; E-Mails: gvivienh@gmail.com (G.V.H.), erwan.lequentrec@orange.com (E.L.Q.) \\ ${ }^{6}$ School of Information Technology, Deakin University, Melbourne, VIC 3125, Australia; E-Mail: josephine@tunapanda.org \\ ${ }^{7}$ Centre for Global Health, Department of Neurology, Technical University of Munich, 81675 Munich, Germany; \\ E-Mail: andrea.winkler@tum.de \\ ${ }^{8}$ Department of Technology Systems, University of Oslo, 2007 Kjeller, Norway; E-Mail: josef.noll@its.uio.no \\ * Corresponding author
}

Submitted: 30 October 2019 | Accepted: 24 March 2020 | Published: 14 May 2020

\begin{abstract}
The concept of digital literacy has been defined in numerous ways over the last two decades to incorporate rapid technological changes, its versatility, and to bridge the global digital divide. Most approaches have been technology-centric with an inherent assumption of cultural and political neutrality of new media technologies. There are multiple hurdles in every stage of digital literacy implementation. The lack of solutions such as local language digital interfaces, locally relevant content, digital literacy training, the use of icons and audio excludes a large fraction of illiterate people. In this article, we analyse case studies targeted at under-connected people in sub-Saharan Africa and India that use digital literacy programmes to build knowledge and health literacy, solve societal problems and foster development. In India, we focus on notable initiatives undertaken in the domain of digital literacy for rural populations. In Sub-Saharan Africa, we draw from an original project in Kenya aiming at developing digital literacy for youth from low-income backgrounds. We further focus on Senegal, Mali, Burkina Faso and Tanzania, where field studies have been conducted on the use of digital technologies by low-literacy people and on how audio and icon-based interfaces and Internet lite standard could help them overcome their limitations. The main objective of this article is to identify key performance indicators (KPIs) in the context of digital literacy skills as one of the pillars for digital inclusion. We will learn how digital literacy programmes can be used to build digital literacy and how KPIs for sustainable development can be established. In the final discussion, we offer lessons learned from the case studies and further recommendation for stakeholders and decision-makers in the field of digital health literacy.
\end{abstract}

\section{Keywords}

digital inclusion; digital inequalities; digital health; digital literacy; health literacy; Internet lite; key performance indicators; sustainable development goals

\section{Issue}

This article is part of the issue "Digital Inclusion Across the Globe: What Is Being Done to Tackle Digital Inequities?" edited by Bianca C. Reisdorf (the University of North Carolina at Charlotte, USA) and Colin Rhinesmith (Simmons University, USA).

(C) 2020 by the authors; licensee Cogitatio (Lisbon, Portugal). This article is licensed under a Creative Commons Attribution 4.0 International License (CC BY). 


\section{Introduction}

In our modern era, Information and Communication Technology (ICT) has been a key dominant factor in bringing innovation change and sustainable development. Sustainable development is the first key concept in this article. The concept has been defined in many different ways in the body of knowledge but, at its core and in practice, it requires the integration of economic, environmental and social objectives across sectors, territories and generations (Emas, 2015).

In this article, we are referring to the sustainable development concept as understood in the terms of the United Nations Development Programme (2017), best known as the 17 Sustainable Development Goals (SDGs) of the 2030 Agenda for Sustainable Development. The leading SDGs framework for international cooperation officially came into force in 2016, proclaiming access to the Internet as a basic human right and fundamental for achieving the SDGs. Each of the 17 SDGs has specific targets to be achieved by 2030 and, in this article, our focus is on the relation of digital technologies and SDG3 Health and SDG4 Education.

Digital technologies play an important role in providing insights into people's activities, opinions, health and everyday lives. Digital health, the second key concept in this article, refers to the use of digital technologies for health and is used as an overarching umbrella for eHealth including mHealth (World Health Organization [WHO], 2019a, p. X). However, there are almost four billion people who do not yet have access to such digital public goods, Internet and basic information on health and education. The digital divide is primarily relevant for people that are unable to access or afford technology due to certain characteristics like gender, socioeconomic category, place of residence (urban/rural), and levels of literacy (Hargittai \& Hinnant, 2008; Radovanović, Hogan, \& Lalić, 2015).

As many scholars have noted, the digital divide is also a divide of literacy and skills (Radovanović et al., 2015; van Dijk, 2005; Warschauer, 2002). Therefore, Internet access is still seen as a necessary condition for sustainable development and many people could more practically engage with the technology if they had the basic skills. In the fourth industrial revolution, digital literacy presents a crucial empowering agent in a governmental, economic and educational setting, as work and personal lives become increasingly technologised. Thus, digital literacy is needed for providing sustainable development and is the relevant factor for bridging this digital divide. Similarly, health literacy is used to describe people's abilities to engage with health information and services (Dodson, Good, \& Osborne, 2014, p. 1) and plays an important role in accelerating towards the SDGs (WHO, 2016).

Another key concept, and challenge, is that there are no universal key performance indicators (KPIs) for certain aspects of digital society development. Therefore, there is an urgent need for framing and developing KPIs for digital literacy. However, there are several issues here, such as how sustainable development is defined, and whether one is measuring the level of sustainable development or the consequent impact of the sustainable development on aspects of society (Radovanović \& Noll, 2017).

This article aims to identify KPIs for sustainable development related to digital literacy. The research questions we are posing here are how digital literacy programs can be used to build knowledge and health literacy, and in the context of digital literacy, how KPIs for sustainable development can be established.

The article is organised as follows: After reviewing the KPIs in the sustainable development and digital literacy context, we present the case studies that developed the KPIs for sustainable development in various country contexts from Sub-Saharan Africa and India. Throughout the article, we present the methodology in regard to each case study, and the main findings in each, discussing the learned lessons. Finally, we provide a conclusion and further recommendations that could be useful for further research and development of the KPIs for digital literacy and digital transformation centres.

\section{Literature Review}

This section addresses the definitions of KPIs in the social context and the digital literacy skills definition in the current technological surroundings, through the literature overview.

A KPI is defined as a set of criteria and measures focusing on the aspects of institutional, individual or project performance that are critical for the success of the organisation or a project. KPI Management has been widely practised by numerous organisations and companies in recent years and, therefore there is a need for more representative performance measures and metrics to reflect the performance of new digital environments.

A performance measurement system plays an important role in managing projects as it provides the information necessary for decision-making and actions. It is essential to measure the dynamics in sustainable development environments so that timely action can be taken. The purposes of measuring project and organisational performance are (1) to identify the success of the project, (2) to help the organisation understand its processes, confirm what they know or reveal what they do not know, (3) to examine if the stakeholders' needs are being met, (4) to identify where problems exist and where improvements are necessary, and (5) to show if planned improvements actually took place (Gunasekaran \& Kobu, 2007; Parker, 2000).

The KPIs approach has also been used to set up frameworks for the assessment of the impact of knowledge management on organisational performance in education (Rodrigues \& Pai, 2005), business (Carrillo, Robinson, Anumba, \& Al-Ghassani, 2003), and other settings. According to Day and Bobeva (2006), in education, 
KPIs are used to meet the objectives and strategic plans of a high education institution. Cox, Issa, and Ahrens (2003) differentiate between quantitative and qualitative measures of success. Their qualitative performance indicators include safety, turnover, absenteeism and motivation. Sohail and Baldwin (2004) carried out a study in low- and middle-income countries in which they offer 67 performance indicators related to socio-economic issues such as enterprise development, poverty alleviation, and empowerment. Despite the extensive research and progress in other areas (industry, management, economy), there is no general agreement on a set of KPIs for sustainable development and digital inclusion projects to date, and the current research in measurement for social projects is relatively limited.

Therefore, there is a need for identifying and establishing the KPIs for measuring relevant sustainable development factors such as digital literacies and implementing them into sustainable infrastructures. Regardless of these limitations, it is important to identify, clarify and frame the perception of KPIs in different types of research and development projects carried out in different contexts to share the best practices and to expand the existing frameworks of KPIs for future projects.

Literature review shows that the performance measurement of managerial and social-related projects is slowly moving away from traditional measures such as cost, time and quality towards a mix of quantitative and qualitative measures.

\section{Digital Literacy and KPIs}

The theoretical understanding of digital literacy is expansive in its purview, encompassing various facets of human-technology relations. Some of these incorporate skills and competencies while others harness multi-literacies, adaptation and creation viewed through various intersecting new media-connecting devices. A decade ago, some scholars such as Haythornthwaite (2007) stressed that digital literacy requirements include competencies in finding, processing, producing, and communicating information, and it also implies fluency in online technologies, communication norms, and programming environments. Needless to say that defining digital literacy is beyond the scope of this article, as ideas and initiatives around digital literacy keep changing according to the needs of individual low- and middleincome countries. However, these overarching theoretical understandings have often been incorporated in various definitions as well as country frameworks, especially in high-income countries. To this end, UNESCO (2018) set up a task force to define and measure digital literacy. After a thorough review of national frameworks from more than 43 countries across all regions, the following definition was adopted:

Digital literacy is the ability to access, manage, understand, integrate, communicate, evaluate and cre- ate information safely and appropriately through digital devices and networked technologies for participation in economic and social life. It includes competencies that are variously referred to as computer literacy, ICT literacy, information literacy, and media literacy. (UNESCO, 2018, p. 21)

This standard definition embodies many important facets of widely accepted theoretical models of digital literacy life skills, competencies, critical thinking and knowledge creation. We can distinguish the following types of digital literacy skills: formal operational skills to navigate the Internet, information retrieval and analytical skills, content creation skills and media literacy skills. We believe that various dynamics and forms of digital divide will intervene differently in each of these skills. In Ireland, there is the incorporation of concepts like coding, programming, computational thinking, logic and critical thinking into the concept of digital literacy (Smith, 2017). Digital literacy, as seen in most high-income countries, incorporates multiliteracies/multimodal dimensions-which are the technical, cognitive, and social-emotional dimensions. Under the rubric of 'multiliteracies' or multimodal literacies, frameworks are shaped and expanded, and thereafter KPIs of digital literacies are developed to measure and analyse the success of sustainable development. For example, in the widely used digital capability framework (used in the UK), seven elements of digital literacy are included in the capability framework. The framework is developed around the idea of digital literacy as 'capabilities' emphasising on digital citizenship along with notions of identity, wellbeing, rights and responsibilities (Brown, 2017). According to Llewellyn (n.d.), this framework can be seen as a strategic management toolset designed to help companies innovate leading to enable business transformation and help companies analyse their current situation. Similarly, the digital competence framework widely used in European countries (DigComp 2.1; see Carretero, Vuorikari, \& Punie, 2016) identifies five components of digital competence. Keywords like competencies, literacies, skills, and capabilities play a crucial role in conceptualising the idea of digital literacy and KPIs related to projects or initiatives. Most national frameworks in the low- and middle-income countries like India and Kenya conceptualise digital literacies only around the idea of competency and skill, which is too narrow a set of competencies, often creating narrow KPIs.

These different understandings of digital literacy emphasise two key points: Firstly, KPIs will vary according to the definition, framework and goals of the country through which initiatives and projects are run. There is no one-size-fits-all digital skills assessment for measuring the success of implemented programmes (Radovanović \& Noll, 2017). Secondly, a comparison of the KPIs of the low- and middle-income countries with high-income countries or an imitation of KPIs from high income countries may be problematic as it may completely de- 
contextualise the former. The socio-economic and cultural contexts of low- and middle-income countries are different. Furthermore, understanding the heterogeneity of countries is important, but that would not be enough to create a solid KPI framework unless the heterogeneity of programmes and projects is well understood. Deconstructing the KPIs is crucial in understanding and creating them.

In the following sections, we will go into detail on how KPIs have been established after casework in the Global South. The cases were selected as a result of a longstanding collaboration with various actors in the projects that aimed to implement digital literacy to achieve SDG3 and SDG4 and further digital transformation. We analyse case studies targeted at underconnected people in Sub-Saharan Africa and India that use digital literacy programmes to build knowledge and health literacy, solve societal problems and foster development. In India, we focus on notable initiatives undertaken in the domain of digital literacy for rural populations. Despite being one of the faster-growing economies in the world, there is a visible gap between rural and urban literacy rates, there is also a wide gap between male and female literacy levels. India ranks as low as 134 in the ICT Development Index ranking out of a total of 176 countries (International Telecommunication Union, 2017). India's literacy rate is close to $74 \%$ (Census 2011, n. d.). Functional literacy rates might be much lower given the potentially questionable measuring mechanism of this national data today.

In Sub-Saharan Africa, we draw from an original project in Kenya targeted at developing digital literacy for youth from low-income backgrounds. According to data from the Communications Authority, internet penetration in Kenya is at $90 \%$ with 51.1 million users. The government has a long-term development plan that aims to transform the country into a knowledge-based economy by utilising ICTs for development and growth (PMO Kenya, 2017). This is an opportunity to leverage youth and utilise human capital to raise labour productivity.

We further focus on Senegal, Mali, Burkina Faso and Tanzania, where field studies have been conducted on the use of digital technologies by low-literacy people and on how audio and icon-based interfaces and the Internet lite standard could help them overcome their limitations. West Africa has experienced significant progress in mobile service usage over the past few years, but it remains behind other emerging markets. Unique mobile Internet users represent $26 \%$ of the population, nearly doubling over two years (2017-2018) but remains below the penetration rate in Lower-middle income countries (33\%) and comparable to the Sub-Saharan African average (22\%; GSMA, 2019). Finally, Tanzania is facing a growing number of people connected to Internet and communication services, especially through mobile technology, with $42 \%$ of the population subscribing to a mobile service in 2018, and more than 8 million new mobile Internet subscribers added since 2010 (GSMA, 2019). However, the rural-urban gap in Internet connectivity is widening; while $86 \%$ of rural citizens have no access to the internet, $46 \%$ are connected in urban areas (Research ICT Africa, 2017).

In Section 4, we briefly present and synthesise each of the methods used in case studies respectively. The detailed case studies are presented in the following sections.

\section{Methodology}

Case studies from India focus on two nation-wide digital literacy initiatives - the first initiative, PMGDISHA, undertaken by the Government, and the Spoken Tutorial initiated at the Indian Institute of Technology Bombay using a self-learning method. These two case studies were selected as they have different objectives and methods of imparting digital literacy-the first used the offline and trainer-based method, exposing digital skills to lowliterate people, and the other used the self-learning hybrid method (online and offline) to impart the digital skills to students who wanted to learn different skills by themselves. We used the secondary resources and the existing literature for these case studies. In the study we have answered two research questions: how digital literacy programs can be used to build knowledge/education and digital skills and how KPIs for sustainable development can be established.

The Tunapanda case study in Kenya uses empirical data obtained by the Tunapanda Institute and employs a mixed-method approach. The data were tested by qualitative thematic analysis and presentation guided by theoretical tools and approaches obtained through desktop analysis and library research. The case study observes how youth employability and entrepreneurship can be used as KPIs in digital literacy initiatives. The study observed 362 youths who graduated from the Tunapanda program and their pathways following the program.

The case studies from West Africa use ethnographical methods. The Senegal study relies on a field experiment conducted by Zouinar and Ndiaye (2015) surveying 20 low-literate mobile phone users between 22 and 52 years of age. Based on a literacy assessment, they are classified into three levels of literacy: illiterates (7; users who have never been to school, are unable to read and write in any language but can have some numeracy skills), semi-literates (10; users who left school very early or went to Arabic school, who can read, understand and write simple phrases in one language and have basic numeracy skills) and advanced semi-literates (3; users who can read, partly understand and write complex sentences in Arabic, French or Wolof). Other experiments present a qualitative survey based on interviews conducted with four subjects corresponding to the first two levels of low-literacy described in Section 7.1, illiterate and semi-literate. These subjects are recruited from recent Malian immigrants in France and can call and use some phone features such as the camera, radio and music. The case study in Burkina Faso uses a focus group ap- 
proach to investigate the use of digital financial services. In Tanzania, the researchers designed a communitybased non-randomised controlled study, as a method, to test the effect of a digital health intervention (DHI) within the "Non-Discriminating Access for Digital Inclusion" project (hereafter only Digl project). A questionnaire with 42 disease-specific health-knowledge questions was developed before quantitative data collection. At the moment, the study is on-going with 596 recruited participants. So far, only preliminary results from the first stage are available. Data collection will end in May/June 2020. Findings will indicate the diseases-specific health literacy level in the two groups, intervention $(N=298)$ and control $(N=298)$, before and after implementation of the DHI. The participants are followed for one year.

In the following sections, we are presenting detailed case studies from India, Kenya, West Africa, and Tanzania.

\section{Case Studies from India}

\subsection{PMGDISHA and Spoken Tutorial: An integrated Approach to Digital Literacy}

Digital literacy has become an essential tool for the economic and social development of people's lives. However, achieving digital literacy is a challenging task due to socioeconomic factors like low literacy levels (Bureau, 2018), poverty, inadequate local content, absence of infrastructure and social inequalities. Therefore, there have been several efforts to equip the digitally illiterate rural population with digital literacy training, including the National Digital literacy Mission (NDLM) launched in 2014, the Pradhan Mantri Gramin Digital Saksharta Abhiyan, also known as Prime Minister's Village Digital Literacy Mission (PMGDISHA) in 2017, and Spoken Tutorial in 2009. The analysis of these notable initiatives will help identify the current KPIs and help establish KPIs that could be relevant for future project performance to enhance digital literacy in low- and middle-income countries such as India and bridge the digital gap between urban and rural areas.

\subsubsection{PMGDISHA}

This was a digital literacy initiative by the Government of India to make 60 million rural people digitally literate by March 2019. In this scheme, one member from each household in the village is digitally illiterate, in the age group 14-60 years, to undergo 20 hours of digital literacy training. As an outcome, the learner should be able to understand the basics of digital devices, browse the Internet, carry out a cashless transaction, etc. The competencies of learners are assessed through an online evaluation test consisting of 25 questions which is conducted by a national certifying agency. This performance test focuses on testing the information retention of the learners without any evaluation of digital skills. This reduces the accuracy of the results.
As PMGDISHA reaches a large-scale rural population belonging to a diverse socio-cultural background, skilltesting becomes a challenging task. There is an unavoidable trade-off between the cost-effectiveness of the resources deployed and the accuracy of the test. Accuracy is dependent on the questions framed, the environment in which they are conducted, adequate training of the trainers and the ability to apply these skills in daily life.

In the case of PMGDISHA, KPIs needs to be integrated from the beginning of the project instead of relying only on assessment studies or social auditing. The impact assessment study conducted by the Council for Social Development for NDLM (a precursor of PMGDISHA), wherein three KPIs were used to measure the success/failure of the implementation. These three KPIs were (1) whether trained candidates can use the digital devices effectively, (2) analysis of the day-to-day application usage and (3) the ability to use digital devices after training. Other qualitative benefits include improvement in confidence levels, knowledge and awareness.

As a large-scale project, PMGDISHA must have an inbuilt feedback and monitoring mechanism to evaluate every stage in the project. This can be done by integrating KPIs based on outcomes and user appreciation in the project. Similarly, the user appreciation-based indicator would help to fine-tune project components such as the training of trainers, training materials to cater to diversity in literacy, knowledge levels, and other socio-economic parameters of the leaners.

\subsubsection{Spoken Tutorial}

The Spoken Tutorial project began at the Indian Institute of Technology Bombay in 2009 to promote IT literacy for education and employment for college students. The tutorials consist of a 10-minute-long audio-video tutorial using screencast technology. These tutorials aim to teach various programming languages like $\mathrm{C}++$, Java, Python, graphic and circuit design tools amongst others to a target population consisting of students, working professionals, and teachers. According to Moudgalya (2017), screencast technology creation policies produce a flexible and easy web-based e-learning experience by including elements like free and open source software, pedagogy of self-learning for beginners, low bandwidth and small screen devices, accessibility without Internet. Due to its flexible approach, it has been used in 36000 college lab courses, and ten universities have announced they will be using screencast technologies for their lab courses. Apart from user-friendly content policy and methods, there is accentuation that Web-based e-learning comes with its shortcomings, highlighted through user feedback. Feedback comes from a Web-based e-learning systematic usability scale questionnaire and self-efficacy questionnaires which are based on the KPI called 'user appreciation.' The user appreciation indicator is used to know whether the project satisfies the needs of the user. In the case of screencast technologies, this indicator is used to 
understand how the learners perceive and understand the tutorials.

Eranki and Moudgalya (2012) presented a study on the relationship between behavioural interventions and user preferences while using screencast technologies. Participants were divided into novice and experts based on a pre-test questionnaire and their Web-basede-learning preferences were identified using the systematic usability scale questionnaire. Using a systematic usability scale, 20 questions are framed to understand user preferences and experiences in using STs (Eranki \& Moudgalya, 2012, p. 42). Based on learner preferences, five feature sets were identified: layout, search, interface, link/buttons/menus, and alphabetical Index. These were classified and clustered into different categories. The study showed that clusters which comprise of novices, preferred single-page interface, standard colour layout, study plan index, search filters and dynamic drop down as compared to the cluster which denotes experts, who preferred multipage, multi-colour, study plan index and dynamic dropdowns (Eranki \& Moudgalya, 2012, p. 42). User centrism of this indicator leads to the optimisation of project parameters, thereby leading to maximum output.

\subsection{KPIs for Self-Sustainable Development}

Dale and Newman (2005) found in their study that universal development requires a complex interdisciplinary approach beyond what is found in traditional environmental education. In diverse socio-economic and cultural contexts, digital literacy can be successfully leveraged to reach out to a greater number of students, including those to whom education was previously not easily accessible, and help to promote learning, as well as exposing students to the technical skills required for many occupations (Budhedeo, 2016). Integrating the KPIs from the beginning of digital literacy imparting projects will help to measure the performance-based assessment, knowledge-based assessment, and self-assessment of the learner (Carretero et al., 2016). KPIs specifically designed for digital literacy will increase the knowledge in each domain, including education, access to health services and improving livelihoods, which can be mapped at household and village levels.

Programs with integrated KPI like PMGDISHA and Spoken Tutorial will not only give exposure to digital skills but also allow learners to improve their ability to utilise their digital skills in a meaningful way. These kinds of participatory and community-oriented skilling programmes enable first-generation learners to have greater access to education, health and information services, thus improving their lives. Going forward, combining the basic digital literacy program PMGDISHA with Spoken Tutorial from the beginning of student life would transform the digital education system and prepare youth for the future. If both the government and other sectors join hands with such community-oriented initiatives, 53 million livelihoods will be created by 2021 , assuming a job- to-user ratio in India of 1:10 and a local language Internet user population of 536 million by 2021 .

\section{Case Study on Digital Literacy Skills Training for Youth in Kenya}

\subsection{The Digital Skills Gap in Kenya}

A report released by the International Labour Organization in 2018 warned that unemployment levels are rising more than job creation and economic sustainability. Kenya has a working-age population of 25.5 million, which translates to over half the country's total population. This number is projected to swell to 39.2 million by 2035 . Yet, one in every five Kenyan youth of working age is unemployed. In Nairobi alone, unemployment stands at $14.7 \%$, with more women (19\%) compared to men (11\%) living without a job. While formal sector employment did grow in Sub-Saharan Africa since 2000, this development unfortunately lagged behind population growth, resulting in fewer opportunities in the formal labour market for the increasing numbers of Africa's young school and university graduates.

Youth living in urban slums face additional barriers such as poverty and gender, making them least suited to reap the benefits of digital inclusion. In Kibera for example, the lack of affordable internet access and devices, and being limited to no digital capabilities lock out these youths who have the potential to gain digital skills that can give them access to entry-level digital jobs.

Regarding gender inequality, the labour force participation for women stands at a global average of $54 \%$ compared to $81 \%$ for men. This has implications in internet connectivity, going by the available figures. For instance, on connectivity, nearly $45 \%$ fewer women than men have access to Sub-Saharan Africa (Intel Corporation, 2013).

The solution for these challenges implies, firstly, job creation. Equipping youth with skills to become entrepreneurs, improve access to financing, and championing small and medium-sized enterprises will help increase opportunities to earn and save. Secondly, skilling the workforce and skills development in STEM and ICT are key components in Sub-Saharan Africa's transformation and economic growth. Thirdly, closing the gender gap is crucial. Although there are many interventions to bridge the digital gap, there is a need to invest in equipping youth with skills that will enable them to look for employment and create opportunities for wealth and jobs both locally and globally.

\subsection{The case of the Tunapanda Institute}

The Tunapanda Institute is an ICT vocational training centre in Kenya's largest urban informal settlement, Kibera. Started in 2014, the organisation runs three-month digital skills training for local youth aged between 18 and 30 years. The program aims to close the digital divide in 
Kibera by ensuring the youth can get entry-level jobs in ICT or start ICT-based entrepreneurial ventures. The organisation receives over 300 applications for the training program but is only able to accommodate 30 trainees per cohort. Access to quality education is a major challenge in Kibera with $80 \%$ of the schools being communityowned schools that are heavily under-resourced and lack basic classroom infrastructure. This not only results in high dropout rates in primary and secondary school while those who manage to finish high school may not be able to enrol at university due to the high cost of education and high cut-off grades. Thus, Tunapanda looks for youth who, despite their previous grades, have a growth mindset, ability to lead and work in teams and have clarity as to why the training would be beneficial. The project-based curricula focus on equipping the youth with employable and entrepreneurship skills in technology and digital design. These are buttressed with soft skills such as communication, growth mindset, and personal branding. The first month of the program focuses on technology; the trainees are taken from basic computer skills to more advanced skills in becoming digital creators. The modules mainly focus on web and mobile development. The second month blends the design thinking methodology and is followed by design in the second month, which adopts the design-thinking methodology for the design of digital products such as websites and mobile applications. In the third month, the trainees focus on building products for the community around them. They take part in researching challenges faced by the community and designing relevant and sustainable solutions. The trainers also focus on preparing steps after graduation depending on the trainee interests and the Tunapanda pathway model. The program encourages peer-to-peer learning through sharing of computers and team projects. The teams have weekly presentations to their fellow trainees who give them constructive feedback, which helps with confidence-building.

\subsubsection{Digital Literacy KPIs}

Kenya does not have a framework for digital literacy KPIs. The definition has mostly been guided by workforce requirements, which is competence in the use of ICTs. However, this definition is limiting as it leaves out other forms of literacy, such as the ability to create digital content, digital identity, online privacy and safety.

Through thematic analysis and direct observations and outcomes after the program trainees went through, Tunapanda developed a set of indicators to measure the success of the training program against the following KPIs:

- Number of graduates joining the Tunapanda journeymen program;

- Number of graduates in employment;

- Number of graduates joining start-up incubator programs.

\subsubsection{Number of Graduates Who Complete the} Journeymen Program

Tunapanda invites applications from a set number of trainees to join the organisation's apprenticeship program. Some $15-20 \%$ of graduates join the 8-month program in which they are mentored in an area in which they would like to develop expertise and is relevant to the organisation's mission. They also become coaches supporting the trainers for the next two cohort programs. After successful completion, they join the journeymen program where they become trainers and also work on the organisation's income-generating activities. Currently, $97 \%$ of the organisation's team are graduates of the program and contribute not only to the training program but also to $75 \%$ revenue generated to run the organisation.

\subsubsection{Number of Graduates in Employment}

Over the years, Tunapanda has developed partnerships with local companies enabling the organisation to place graduates into employment. The organisations send the graduates' resumes to potential employers and arrange for interviews. Successful candidates can secure jobs and Tunapanda charges placement fees to the employer. The graduates can get entry-level jobs in market research for digital products, customer service, and technical support. Tunapanda has several success stories of graduate placement with $68 \%$ of the graduates being employed.

\subsubsection{Number of Graduates Joining Start-Up Incubator Programs}

The third pathway is entrepreneurship where graduates are placed in start-up incubators. Tunapanda has partnered with Somo Africa, a social enterprise incubator in Kibera. The program provides training, mentorship and start-up capital for these budding entrepreneurs. The organisation has also supported three female graduates in joining a one-year technology and entrepreneurship start-up incubator program in Ghana. Two of the women's start-up ventures were funded after completion of the program.

\subsubsection{Replicability}

Tunapanda Institute's model was initially designed for replicability at a minimal cost. By empowering learners to quickly become coaches and trainers, Tunapanda's model lowers barriers to entry in the training profession and lowers costs for schools to run. The model also avoids competition for technically-enabled teachers, which is a big problem in low-income regions. By working with other organisations, the model generates robust and replicable processes for setting up, running and growing advanced digital training facilities even in the most remote of areas. One successful mission has 
been with the Learning Lions Project (IT education for remote Africa) in Turkana, a remote part in Northern Kenya, where two graduates of Tunapanda Kibera successfully launched a clone of the program. By distributing and creating only open source software and open learning resources, the Institute minimises costs for replication and empowers people to customise the curricula to suit their local contexts. Tunapanda's KPIs aim to ensure that the program graduates have better earning and learning opportunities, for improved livelihoods.

Digital literacy is the key to ensuring the effective use of ICTs and digital media. The Kenya case study shows that it can contribute to not only building a skilled workforce but also to increased earnings and igniting entrepreneurship among youth. This directly contributes to SDG4, SDG5, SDG7, SDG10 and SDG11.

Although there is anecdotal evidence of the global spread of internet connectivity, there is little empirical data that captures the reality of this phenomenon in Kenya regarding the uptake, infrastructural development, policy formulation and implementation on matters of internet connectivity in Kenya, the involvement of various actors, and how marginalised groups such as the youth are involved in these processes. The current case study fills this gap. In other words, this case study contributes to country-specific literature on the opportunities available as well as the uptake of digital literacy.

Specifically, the case study demonstrates the viability and impact of tech hubs in the Kenyan context; it shows the relationship between skills obtained in such contexts and employability and suggests measures to be taken if challenges associated with the foregoing are to be overcome.

\section{Case Studies on the Uses of Mobile Services in West Africa}

In this section, we present two case studies, one from Senegal and another from Burkina-Faso, to illustrate how low-literacy users overcome their limitations and the potential of voice, or sound more generally, to increase their use of mobile phones.

\subsection{Mobile Voice and Text Usage among Low-Literacy People in Senegal}

This subsection reports the main findings from an ethnographic study conducted in Senegal by Zouinar and Ndiaye (2015). The study aimed to understand how literacy affects the use of a mobile phone to design new devices and services that can be used by individuals with a low level of literacy.

Three patterns of usage corresponding to the three levels of low literacy have been identified: basic use, limited use and quasi-autonomous use. Basic use consists of very limited usage of mobile phone, mainly receiving calls from family members, friends and clients. Some basic users can make a call from the call history or notebooks. Others can play music or radio on the phone. However, they do not use text messaging or the contacts list. Limited use involves receiving and making calls but not using a text message. Some limited users manage contacts or require assistance from close relatives or friends to use other features such as changing the phone settings, reading, writing or sending text messages. Quasi-autonomous use is associated with users who can read, write and send text messages. However, they need to rely on literates to write complex messages.

It turns out that low-literates develop strategies to overcome their limitations. They rely more on voice than text. This is consistent with the findings from a study conducted by Chipchase (2008) in Asia (India, China and Nepal) which suggests that illiterate mobile users can call and answer incoming calls but cannot use features that require text editing. They rely on memorisation and the use of proximate literates to assist in phone use. These findings suggest that access to ICT is less affected by individuals' level of literacy. However, usage intensity could be affected. Therefore, digital literacy KPIs should put more emphasis on the abilities needed to use ICT services.

\subsection{Using Sonification to Increase the Use of Mobile Services}

This section reports the results of two experiments that assess the impact of sonification on the use of mobile services.

The first experiment was conducted by Zouinar and Boyer (2016) to evaluates the effectiveness of a new user interface that embeds voice in the local language (Bambara) and explicit icons to save contacts, write SMS, dial a phone number, initiate a call and use the list of contacts. Two types of voice assistance were proposed: one that delivers a message to assist the user in doing an operation with their phone (e.g., saving a contact), and another that links vocal messages with icons to make them understandable to the user.

However, these experiments are very limited in the usage of text message and the Internet. Each was subjected to six scenarios:

- Saving a contact following a call;

- Saving a contact from the call history;

- Selecting a predefined SMS and sending to contacts from the phonebook;

- Initiating a call from the list of contacts;

- Dialling a phone number;

- Identifying a series of icons.

The main findings suggest a strong potential of vocal assistance to support the use of ICT by low-literacy individuals. Subjects showed a strong preference for vocal assistance, especially in their mother tongue, suggesting that digital literacy KPIs should include the ability to use vocal communication channels to interact with ICT services. 
The second experiment uses a focus group approach to investigate the use of digital financial services in Burkina Faso (Le Ravazet \& Pringent, 2017). It aims at evaluating the impact of a sound-based prototype of a mobile-money App on usage. The sound-based prototype includes audio-icons, whereby a sound is emitted as the users are about to touch it.

Two samples of users were constructed: a treatment group of 6 individuals who use the sound-based prototype and a control group of 4 individuals who use the typical mobile-money App. The following six scenarios were tested:

- Entering the secret code;

- Viewing the account balance;

- Making an international transfer;

- Topping up airtime;

- Paying a bill;

- Making a national money transfer.

It turns out that sonification has a positive and significant impact on the usage of mobile-money services, the number of participants that successfully passed all scenarios without any assistance is greater in the treated group than in the control group.

These case studies highlight two considerations for the measurement of digital literacy in a low-literacy context:

- Heavy reliance on voice rather than text;

- Reliance on proximate literates.

Regarding the reliance on proximate literates, it means that the assessment of digital literacy skills should go beyond the settings of a specific individual and encompass the skills of other individuals with whom he/she interacts. The surveys conducted in Senegal suggest that low literate people typically rely on literate members of their households or close friends.

However, these specificities are likely to act as constraints regarding the use of ICT for formal or confidential purposes, such as contracts and financial transactions. Therefore, as suggested by the experiments conducted with Malian diaspora and in Burkina Faso, service innovations could be a relevant complement to lower the barriers to using digital services for low-literates.

\section{Case Study on the Digi Project in Tanzania}

The previous sections in this article have elaborated on digital literacy in general; this part will be more specific on the concepts of digital health and health literacy.

The Digl project is a multi-disciplinary project that installs small WiFi information spots providing digital information in rural Tanzania, in areas previously not connected to the Internet. Basic and affordable equipment is installed in local houses, schools, health facilities or centres to connect the villages. The main objective of the study is to assess disease-specific health knowledge six months after part two of the $\mathrm{DHI}$ has been rolled out. The number of correct answers pre and post-exposure will be analysed using McNemar's test. Knowledge scores will be calculated with the answers from the multiple-choice sections and linear regression models will be used when analysing the results. The scores will be adjusted for the confounders: age, education and gender.

\subsection{The Digl Project and DHI}

The actual information spot provides free access to a catalogue of whitelisted pages on the Internet (with text and pictures) and locally stored information, for example, digital health messages. The users also have premium access to heavier webpages, with video streaming, for example. This sustainable and inclusive internet-for-all solution is called Internet lite (Basic Internet Foundation, 2018). Each project village has its local network control centre, as well as a village server, allowing all use of Internet lite in the village to be free of charge.

Internet lite can be accessed either with own smartphones or tablets for public use, located in the information spots. The DHI consists of two parts: (1) a singletime exposure to digital health messages in an animated video format and (2) free access to digital health messages locally stored in a community information spot. The intervention aims to increase health literacy related to specific diseases of public health importance, such as HIV/AIDS, tuberculosis, Taenia solium cysticercosis/taeniosis and anthrax. These are called intervention diseases. The results of the study will be converted into a set of KPIs and are related to (1) the knowledge gained after exposure to the digital health messages, and (2) the knowledge retention resulting from the use of the community information spot.

The digital health messages are provided in several formats, like animated health videos, audio clips, text, pictures and quizzes. They are finalised and to be found online (Digl project, 2020). A screenshot of the web prototype is provided in Figure 1.

The health contents were developed together with physicians, veterinarians, IT professionals, web designers, local communities and digital health researchers and are in line with national guidelines (Ministry of Health, Community Development, Gender, Elderly and Children Tanzania, 2017) and strategy plans (Ministry of Health and Social Welfare Tanzania, 2015; PMO Tanzania, 2015). In the Digl team, the importance of locally relevant content and a local language digital interface in Tanzanian Kiswahili is emphasised. When accessing the digital health messages, users are provided with basic information related to five relevant domains of the intervention diseases:

- Prevalence, to create local visibility about the particular disease;

- Cause/transmission, on how the diseases spread and infect others; 


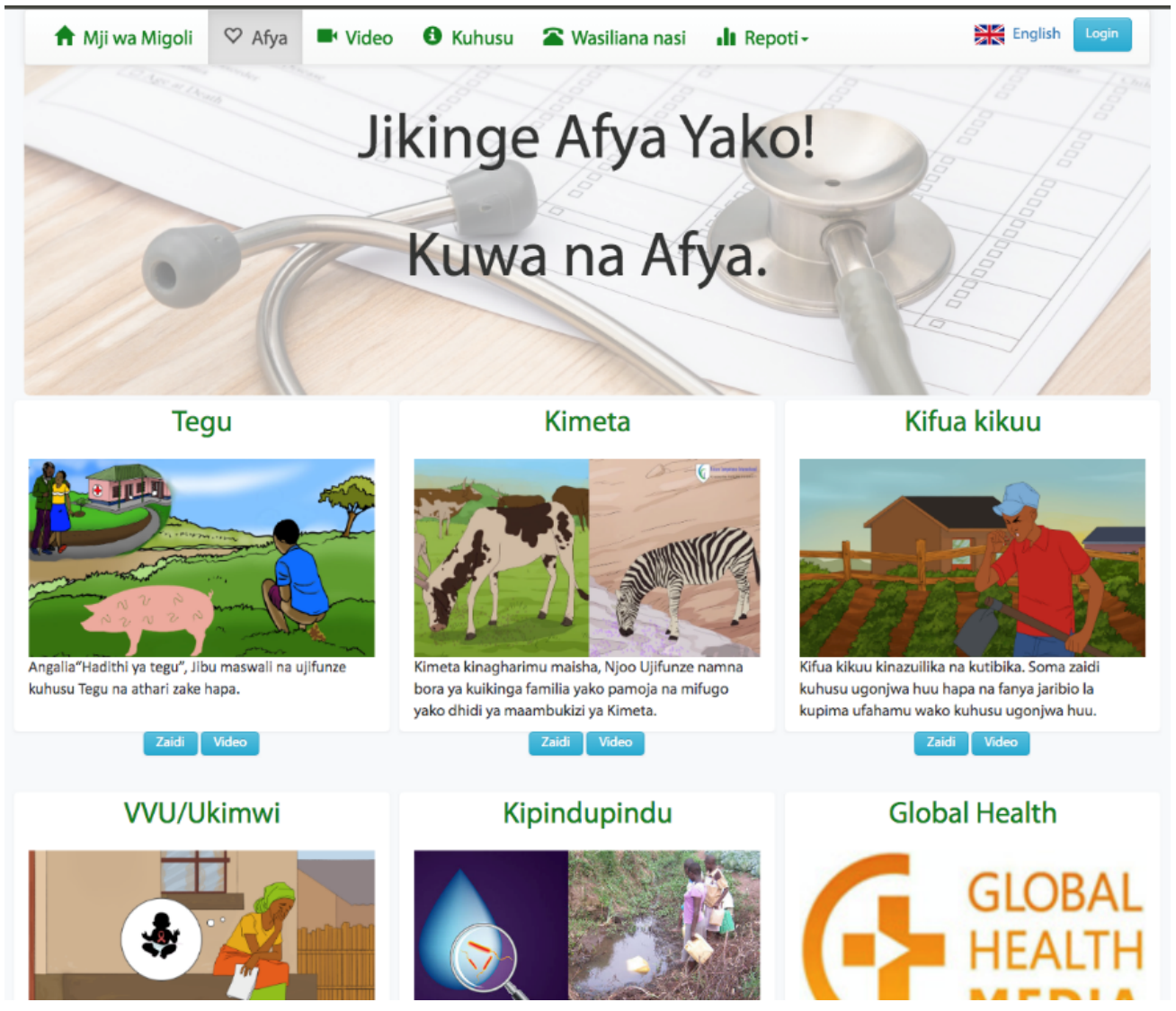

Figure 1. Screenshot from the web prototype developed in the Digl project.

- Symptoms, to promptly detect and treat the diseases medically. The digital health messages encourage and motivate people to seek medical advice if symptoms appear, and will provide contact details to the nearest health clinic;

- Treatment, to show how patients can live healthy lives with the right treatment;

- Prevention, on how people can protect themselves, their families and how to prevent the disease from spreading between individuals and/or in the communities.

The overall goal of increasing health literacy is better disease management, disease prevention, better use of health care services and ultimately the reduction of morbidity and mortality. Sørensen et al. (2012) has captured this in a proposed model for developing health literacy enhancing interventions, as shown in Figure 2. This model is demonstrating the different dimensions of health literacy and shows the link between health care, disease prevention and health promotion.

As shown in the model, it is also expected that the $\mathrm{DHI}$ at a broader level will have an impact on health service use, which again affects health costs, health behaviour and following health outcomes, participation and empowerment, as well as equity and sustainability. However, these are all outcomes that are extremely costly and time-consuming to monitor, measure and evaluate, and would altogether require a study design with a large population enrolled for years beyond the project frame. In the Digl project, the effect of the DHI is measured in relation to knowledge uptake and knowledge retention pertaining to the inner circle representing an arrow in Figure 2 and therefore in more feasible ways, with follow-ups over a year, eventually suggesting KPIs for disease-specific health literacy from knowledge uptake and knowledge retention.

The Digl project further addresses two important aspects of health literacy according to Figure 2, aboveaccess to and understanding of the digital health messages, which can ultimately lead to the appraisal and application of the information. Digital health is essential to achieve sustainable health systems with universal health coverage (WHO, 2019b).

\subsection{The Most Important Outcome: Transforming Results from a Controlled Study into KPIS}

The intervention group was exposed to the digital health messages in an animated health video format, once, just after baseline knowledge questions had been asked. Questions were repeated right after this exposure. This first round will provide KPIs on knowledge uptake by comparing baseline knowledge scores with immediate after exposure knowledge scores in the intervention group and adjusting for changes in the control group. 


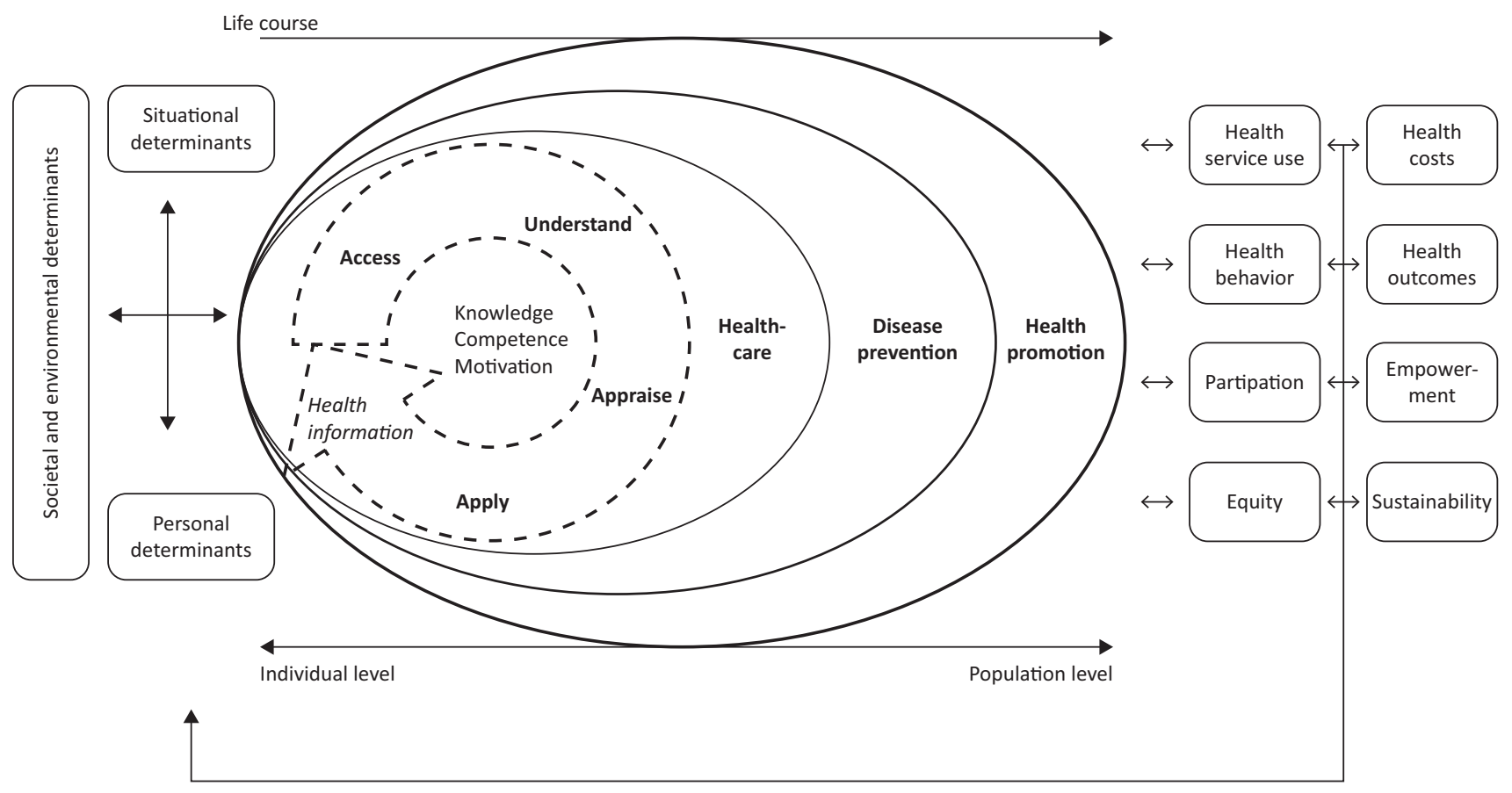

Figure 2. Sørensen et al.'s integrated model of health literacy (2012; with courtesy of Dr. Sørensen).

The KPIs for disease-specific health literacy in the following stage are related to KIPs for digital literacy, as the communities' health knowledge level will only increase as people in the communities are accessing the digital health messages in the community information spots, either with their own smartphones or with the tablet devices in the spots. Knowledge scores for each domain will be calculated individually and the village level, and comparisons between the groups will be performed. The preliminary results from the first stage indicate that disease-specific health literacy scores, in almost all domains, increases after the participant has been exposed to the digital health messages once. In the followups, during the assessment of knowledge retention, both health knowledge and the actual use of the information spots will be assessed. These results will be valuable in light of digital literacy, as the users will have to manoeuvre single-handedly and digitally in the information spots. No assistants are there to show the animations this time. If the use of information spots increases, for example due to an increase in the number of people accessing and watching the animations or taking the health quiz, we know that people are increasing their digital literacy, basically because they are operating, browsing options and gaining knowledge via a digital device.

In this Digl case study section, we have elaborated upon how a digital literacy program; the Digl project with its information spots, Internet lite and digital health messages, can build health knowledge and health literacy by connecting rural people with digital information. The KPIs established from the on-going study within the project will assist in evaluating the $\mathrm{DHI}$ and suggest the revision of both the health content and the user inter- face. This acquired knowledge can be applied in phase II of the project, scaling up by installing information spots with Internet lite access in more villages. The use of digital health messages is still at a very early stage in rural Africa, but development is happening disproportionately fast. KPIs on knowledge retention will be provided at a later stage by following the two groups over time and monitoring the disease-specific health literacy level in the group that has been exposed to the digital health messages as compared to the one which has not.

This approach has the potential to increase health literacy for a broad group of people and the information spots can provide access to other types of information, thus increasing general, digital, computer and information-specific literacy.

\section{Results}

In the research and development world, we are facing the three levels of digital divide: the first level in internet access, the second level in digital literacies and competencies, and finally, the third level-the divide in life opportunities and benefits gained from the first two. Obtaining digital skills is a form of human digital capital and is of crucial relevance for life-long learning, opportunities, and improved livelihoods and sustainable development.

Equally important, increasing digital literacy is one of the targets of the SDGs. Its achievement requires a definition and associated measurement to monitor progress. However, as noted by UNESCO (2018), the specific digital literacy competencies and proficiency levels valued by adults depend largely on their specific country and eco- 
nomic sector contexts. This view is reflected in the cases studies presented in this article.

Here, we briefly summarise the most significant findings from the case studies. We highlight some results that are relevant to the research questions and the lessons learned.

Through the case study analysis, we have shown KPIs that have been developed for digital literacy in various country contexts, from governmental efforts in India to projects in Kenya, Senegal, Mali, Burkina Faso and Tanzania where experiments were conducted on the use of digital technologies by low-literacy people. All these case studies have in common the lack of digital literacies among the population, especially in the rural areas, thus, the difficulty of bridging level three of the digital divide in improved life opportunities. Further, these case studies belong to similar economic and educational background sets and represent low-income countries. Here, we have explored how various digital initiatives and programmes could contribute to overcoming limitations and increasing capabilities. We have also learned how digital literacy programs can be used to build digital and health literacy, and how KPIs for sustainable development can be established.

In India, it was observed how two digital literacy national programs, participatory and communityoriented skilling designed, integrated and measured the $\mathrm{KPI}$ among learners to improve their digital skills in a meaningful way. These literacy programs bridge level 2 and level 3 of digital divide, and they enable firstgeneration learners to have greater access to education and health, thus improving their lives. KPIs such as user appreciation, the ability of the program trainees to use the digital devices effectively and after the training, analysis of the day-to-day application usage and other qualitative benefits are valuable indicators for the similar programs in low- and middle-income countries.

In Kenya, although the country does not have the developed KPI framework for digital literacy strategy, we've learned from the Tunapanda Institute case how a skillslearning driven community is equipping youth with digital skills necessary for the digital transformation and workforce. The Tunapanda Institute developed a set of KPIs to measure the success of the training program based on life benefits upon the completion of digital literacy, such as the number of graduates in employment and number of graduates joining start-up incubator programs. The study contributes by providing direct and indirect beneficiaries of the tech hub idea, which is implemented via the Tunapanda Institute. It also provides information on the gap between the interest in the idea and the availability of opportunity, indicating that only $10 \%$ of the total population of applicants get a chance to undergo the training.

In West Africa, we presented two ethnographic case studies from Senegal and from Burkina-Faso to illustrate how low-literacy users overcome their limitations. Main findings suggest a strong potential of vocal assistance and heavy reliance on voice rather than text to support the use of ICT by low-literacy individuals. The lessons learned from these cases suggest that digital literacy KPIs should include the ability to use vocal communication channels to interact with ICT services.

Finally, in Tanzania, the on-going Digl project and case study presented a set of tentative KPIs that are related to the information uptake and retention after exposure to the digital health messages contributing to the digital literacy and disease-specific health literacy, resulting from the use of the community information spot. The KPIs within the project will assist in evaluating the $\mathrm{DHI}$ and suggest the revision of both the health content and the user interface. We learned from this case study that the use of digital health messages is still at a very early stage in rural Africa, however, ICT development is accelerating.

These case studies from various 'under-connected' countries (countries with low or no connectivity at all) indicate the performance of digital literacy training and initiatives that are dependent on socio-economic contexts and user experience. Therefore, developing KPIs around them is a necessity. We have argued that programmes and initiatives for digital literacies should focus on the ability to use both online and offline content.

\section{Discussion and Conclusion}

The lack of digital literacy is a major obstacle to connecting the 3.6 billion people still cut off from the digital era. We need strong multi-stakeholder collaboration, building internal alliances and partnerships with national and international organisations on digital skills development to extend the benefits of digital technologies and digital transformation. We conclude that for digital literacy to go hand in hand with digital inclusion and social empowerment, it is important that KPIs become an integral part of the digital literacy initiatives and projects. Table 1 presents a summary of the key findings in regard to the $\mathrm{KPIs}$ for digital literacy in various country contexts.

Our findings contribute with three new perspectives in the body of literature. First, these case studies are aiming towards understanding the commonalities to achieve digital literacy and set up the KPI framework in various country contexts. Secondly, the literature based on KPIs and digital literacy tends to focus on a particular digital literacy initiative rather than on setting up the KPIs for that initiative. And third, literature based on developing KPIs for digital literacy does not always adopt a grounded approach. In this study, we present who actually needs digital literacy and how those people can be trained to achieve livelihood opportunities with obtained new skills (employment, mobile phone usage, health information access, etc.).

From the presented case studies, it was observed that the lack of basic digital literacy skills is the underlying factor that connects each of these case studies. Another common indicator of these case studies is the 
Table 1. Summary of KPIs based on case studies.

\begin{tabular}{ll}
\hline Case study country & The main digital literacy KPIs \\
\hline India & The ability to use digital devices effectively; \\
& Analysis of the day-to-day application usage; \\
The ability to use digital devices after training; & The user-appreciation indicator. \\
& Number of youth trained; \\
& Number of trained graduates who were employed; \\
Kenya & Number of trained graduates who choose other career paths. \\
& Ability to change the phone settings of an individual's household members, close relatives \\
or friends & Percentage of phone calls successfully placed; \\
West Africa & Number of an individual's household members, close relatives or friends able to place \\
& a phone call; \\
Number of an individual's household members, close relatives or friends able to read, write \\
or send a short text message. \\
Disease-specific knowledge retention of the participants, after 3, 6 and 12 months; \\
Accessibility of the health information via community information spots; \\
Ability to use health information in day-to-day life.
\end{tabular}

knowledge uptake and retention after the obtained digital skills programs, meaning that the low-literacy users will be able to implement their skills in everyday life, at work, in further education. While national digital literacy programs presented in India, and the ICT vocational training centre in Kenya address the users with some literacy capabilities, the presented experiments and projects in West African counties and Tanzania address illiterate and semi-literate population in rural areas primarily, where the digital skills training relies on sonification and voice and video messages. And finally, the digital literacy training in local language holds the importance in these countries due to a largely illiterate and semi-literate user and enabling the material in various formats would address the various levels of literacy. For example, in India, IT training in the local language through Spoken Tutorials has prepared the youth for better employment opportunities. In Tanzania, the case study uses multiple formats (online and offline) in the DHI in Swahili such as video, audio clips and pictures for those illiterates.

Researchers could further contribute and investigate the whole range of 21st century digital skills to define policies for the development of these important skills so policymakers and governments can act upon it. In particular, Research and Development should focus on the determinants of financial digital skills, critical thinking digital skills, collaboration, and communication digital skills that are underreported and underdeveloped. This would further facilitate the precise framing of the KPIs for different variations of digital skills.

We must move forward and update frameworks, policies and programs. However, it may be challenging to have a one-size-fits-all KPIs digital literacy framework. Governments, Ministries and national stakeholders should aim to ensure that the program trainees have better digital skills and learning opportunities for improved life benefits. Policymakers and researchers need to start with the methodology and create an approach that will address local needs and be replicable to other communities.

One of the solutions would be to offer and implement free online services that require the use of the skills we seek here to impart, along with enough help and tutorials to allow users to self-guide. That would address the matter for $75 \%$ of cases. These solutions are opensource software that can freely be used to create and deliver open learning resources, contributing to the scaling of digital skills programs and further developing the KPIs digital literacy framework.

Through the open-source software and open learning resources for digital skills, we can minimise costs for replication and customisation and address big groups and communities in the local language, thus, it has potential to reach many people and contribute to the digital transformation in the 'under-connected' areas with low literacy levels helping them to join the information society.

\section{Acknowledgments}

This work was co-funded by the Research Council of Norway and the Norwegian Government through the "Non-Discriminating Access for Digital Inclusion" project under project number 267558/H30. Authors Andrea S. Winkler and Josef Noll contributed equally to the conceptual work of the article.

\section{Conflict of Interests}

The authors declare no conflict of interests. 


\section{References}

Basic Internet Foundation. (2018). Keyword basic Internet: Internet lite. Basic Internet Foundation. Retrieved from https://its-wiki.no/wiki/Internet_lite

Brown, M. (2017). A critical review of frameworks for digital literacy: Beyond the flashy, flimsy and faddish. ASCILITE Technology Enhanced Learning Blog. Retrieved from https://blog.ascilite.org/a-criticalreview-of-frameworks-for-digital-literacy-beyondthe-flashy-flimsy-and-faddish-part-1

Budhedeo. (2016). Issues and challenges in bringing ICT enabled education to rural India. International Journal of Scientific Research in Education, 4(1), 4759-4766. Retrieved from http://ijsae.in/ijsaeems/ index.php/ijsae/article/viewFile/1055/726

Bureau, F. E. (2018, September 24). A look at India's deep digital literacy divide and why it needs to be bridged. Financial Express. Retrieved from https://www.financialexpress.com/education-2/ a-look-at-indias-deep-digital-literacy-divide-andwhy-it-needs-to-be-bridged/1323822

Carretero, S., Vuorikari, R., \& Punie, Y. (2016). DigComp 2.1: The digital competence framework for citizens with eight proficiency levels and examples of use. Brussels: European Commission. Retrieved from https://publications.jrc.ec.europa.eu/repository/ bitstream/JRC106281/web-digcomp2.1pdf_ (online).pdf

Carrillo, P. M., Robinson, H. S., Anumba, C. J., \& AlGhassani, A. M. (2003). A framework for linking knowledge management to business performance. Electronic Journal of Knowledge Management, 1(1), 1-12.

Census 2011. (n. d.). Literacy in India. Census 2011. Retrieved from https://www.census2011.co.in/literacy. php

Chipchase, J. (2008). Reducing illiteracy as a barrier to mobile communication. In J. E. Katz (Ed.), Handbook of mobile communications studies (pp. 79-89). Cambridge, MA: The MIT Press.

Cox, R. F., Issa, R. R. A., \& Ahrens, D. (2003). Management's perception of key performance indicators for construction. Journal of Construction Engineering and Management, 129(2), 142-151.

Dale, A., \& Newman, L. (2005). Sustainable development, education and literacy international. Journal of Sustainability in Higher Education, 6(4), 351-362.

Day, J., \& Bobeva, M. (2006). Using a balanced scorecard approach for evaluating an integrated learning environment for undergraduate dissertations. In D. Remenyi \& A. Brown (Eds.), Proceedings of the 13th European conference on information technology evaluation (pp. 198-207). Sonning Common: Academic Conferences and Publishing International Limited.

Dodson, S., Good, S., \& Osborne, R. H. (2014). Health literacy toolkit for low and middle-income countries: A series of information sheets to empower communities and strengthen health systems. New Delhi: World
Health Organization, Regional Office for South-East Asia.

Emas, R. (2015). The concept of sustainable development: Definition and defining principles (Brief for GSDR2015). Retrieved from https://sustainable development.un.org/content/documents/5839 GSDR\%202015_SD_concept_definiton_rev.pdf

Eranki, K. L., \& Moudgalya, K. M. (2012). Evaluation of web based behavioral interventions using spoken tutorials. In T4E 2012: Proceedings from IEEE fourth international conference on technology for education (pp. 38-45). Piscataway, NJ: IEEE.

GSMA. (2019). Connected women: The mobile gender gap report 2019. London: GSMA. Retrieved from https://www.gsma.com/mobilefordevelopment/ wp-content/uploads/2019/02/GSMA-The-MobileGender-Gap-Report-2019.pdf

Gunasekaran, A., \& Kobu, B. (2007). Performance measures and metrics in logistics and supply chain management: A review of recent literature (1995-2004) for Research and Applications. International Journal of Production Research, 45, 2819-2840. https://doi. org/10.1080/00207540600806513

Hargittai, E., \& Hinnant, A. (2008). Digital inequality: Differences in young adults' use of the Internet. Communication Research, 35(5), 602-621.

Haythornthwaite, C. (2007). Social facilitators and inhibitors to online fluency. In Proceedings of 40th annual Hawaii international conference on system sciences. Piscataway, NJ: IEEE. Retrieved from http://www.computer.org/csdl/proceedings/hicss/ 2007/2755/00/27550067a-abs.html

Intel Corporation. (2013). Women and the web: Bridging the Internet gap and creating new global opportunities in low and middle-income countries. Santa Clara, CA: Intel Corporation. Retrieved from https://www.intel.com/content/dam/www/public/ us/en/documents/pdf/women-and-the-web.pdf

International Telecommunication Union. (2017). Measuring the information society report 2017. Geneva: ITU. Retrieved from https://www.itu.int/en/ITUD/Statistics/Documents/publications/misr2017/ MISR2017_Volume1.pdf

Le Ravazet, D., \& Pringent, D. (2017). Conception des tests/réalisation/analyse/rédaction d'un test de sonification [Design/realization/analysis/writing of a sonification test]. Paris: Orange Labs.

Llewellyn, R. (n. d.). Digital capability framework. Rob Llewellyn. Retrieved from https://robllewellyn.com/ digital-capability-framework

Ministry of Health and Social Welfare Tanzania. (2015). The national strategic plan V (2015-2020) for tuberculosis and leprosy. Dar es Salaam: The United Republic of Tanzania.

Ministry of Health, Community Development, Gender, Elderly and Children Tanzania. (2017). National aids control programme. National guidelines for the management of HIV and AIDS. Dar es Salaam: The United 
Republic of Tanzania.

Moudgalya, K. M. (2017). IT skills training through Spoken Tutorials for education and employment: Reaching the unreached. CEC Journal of Digital Education, 1(1), 19-62.

Non-Discriminating Access for Digital Inclusion. (2020). Health information. Migoli. Retrieved from https://migoli.yeboo.com/health_information_ dashboard.php

Parker, C. (2000). Performance measurement. Work Study, 49(2), 63-66. https://doi.org/10.1108/00438 020010311197

PMO Kenya. (2017). The Kenya national ICT master plan 2014-2017. Nairobi: Prime Minister's Office, The Republic of Kenya. Retrieved from http://icta. go.ke/pdf/THE\%20NATIONAL\%20ICT\%20MASTER PLAN\%202017.pdf

PMO Tanzania. (2015). The United Republic of Tanzania one health strategic plan 2015-2020. Dar es Salaam: The United Republic of Tanzania. Retrieved from https://bit.ly/2JQMhJf

Radovanović, D., \& Noll, J. (2017). KPI for social development-Whitepaper. Kjeller: Basic Internet Foundation. Retrieved from https://its-wiki.no/ images/7/7b/KPI_for_socia_development_white_ paper.pdf

Radovanović, D., Hogan, B., \& Lalić, D. (2015). Overcoming digital divides in higher education: Digital literacy beyond Facebook. New Media \& Society, 17(10), 1733-1749. https://doi.org/10.1177/ 1461444815588323

Research ICT Africa. (2017). The state of ICT in Kenya: Report 2017. Cape Town: Research ICT Africa. Retrieved from https://researchictafrica.net/wp/wpcontent/uploads/2019/06/After-Access_The-stateof-ICT-in-Kenya.pdf

Rodrigues, L. L. R., \& Pai, R. (2005). Preparation and validation of KM measurement instrument: An empirical study in educational and IT sectors. Semantic Scholar. Retrieved from https://www.semanticscholar.org/ paper/PREPARATION-AND-VALIDATION-OFKM-MEASUREMENT-AN-IN-Rodrigues-Pai/ dce9b3a326919390004bb4dac3d93bc8e164c48f

Smith, M. (2017). Digital literacy and education. Report by country-Ireland. Brussels: European Literacy Network. Retrieved from https://www.is1401eln.eu/ fotos/editor2/imagens/ir_report.pdf

Sohail, M., \& Baldwin, A. N. (2004). Performance indicators for 'micro-projects' in developing countries. Con- struction Management and Economics, 22(1), 11-23. Sørensen, K., Van den Broucke, S., Fullam, J., Doyle, G., Pelikan, J., Slonska, Z., \& (HLS-EU) Consortium Health Literacy Project European. (2012). Health literacy and public health: A systematic review and integration of definitions and models. BMC Public Health, 12(1). Retrieved from https://bmcpublichealth.bio medcentral.com/articles/10.1186/1471-2458-12-80

UNESCO. (2018). Global framework of reference on digital literacy skills for indicator 4.4.2: Percentage of youth/adults who have achieved at least a minimum level of proficiency in digital literacy skill (Draft Report). Paris: UNESCO. Retrieved from http:// uis.unesco.org/sites/default/files/documents/draftreport-global-framework-reference-digital-literacyskills-indicator-4.4.2.pdf

United Nations Development Programme. (2017). Human development indicators: Kenya. United $\mathrm{Na}$ tions Development Programme: Human Development Reports. Retrieved from http://hdr.undp.org/ en/countries/profiles/KEN

van Dijk, J. (2005). The deepening divide: Inequality in the information society. Thousand Oaks, CA: Sage.

Warschauer, M. (2002). Reconceptualizing the digital divide. First Monday, 7(7). Retrieved from https:// firstmonday.org/article/view/967/888

World Health Organization. (2016). Health literacy and the SDGs. World Health Organization. Retrieved from http://www.who.int/healthpromotion/ conferences/9gchp/health-literacy-sdgs/en

World Health Organization. (2019a). WHO guideline: Recommendations on digital interventions for health system strengthening. Geneva: World Health Organization.

World Health Organization. (2019b). Global strategy on digital health 2020-2024. World Health Organization. Retrieved from https://www.who.int/docs/defaultsource/documents/gs4dh.pdf?sfvrsn=cd577e23_2

Zouinar, M., \& Boyer, E. (2016). Quelsapportsd'une interface utilisateurvocale de téléphone mobile pour les situations d'illettrisme? [What are the benefits of a mobile phone voice user interface for illiteracy circumstances?]. New York, NY: Mimeo.

Zouinar, M., \& Ndiaye, M. A. (2015). Low literacy, social inclusion and the use of mobile phones. In C. Wamala-Larsson, C. Scharff, \& J. Hellstrom (Eds.), Mobile participation: Access, interaction and practices. Newcastle upon Tyne, Barcelona, Berlin, Hangzhou: Cambridge Scholars Publishing.

\section{About the Authors}

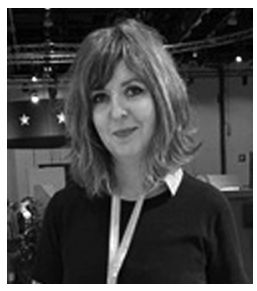

Danica Radovanović (PhD) is a Digital Media Researcher and serves as a digital inclusion advisor at the Basic Internet Foundation. Danica has worked for the United Nations of the FAO as an Information management specialist, she has served as an editor for the ICAF's ChildArt magazine, on digital skills and online safety for youth, and works as a senior researcher. She is a PhD Chevening Scholar, Oxford Internet Institute, a doctorate graduate from the Faculty of Technical Sciences, Novi Sad. Danica has practical and qualitative research skills and her work focuses on digital inclusion, digital literacy skills and digital transformation. 


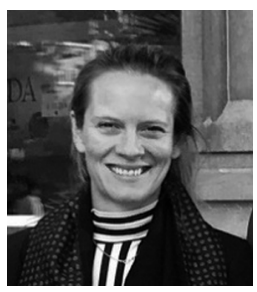

Christine Holst is a Doctoral Research Fellow from Centre for Global Health, University of Oslo. She is the coordinator of the "Non-Discriminating Access for Digital Inclusion" project and she has extensive experience from various countries in the global south. She holds an MPhil in Development Studies, specialising in geography, a bachelor's in African studies and a bachelor's in business and administration.

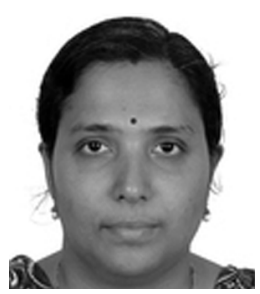

Sarbani Banerjee Belur holds a PhD in Demography from the University of Groningen, The Netherlands. She works on field implementation and impact of technologies in the rural areas in India. Currently, she is a Senior Research Scientist at the Indian Institute of Technology Bombay, Mumbai, India. Her work involves increasing digital outreach to remote rural areas of India, deployment of new technology alternatives for last-mile internet connectivity, community ownership and development of a sustainable business model supporting multi-stakeholder partnerships.

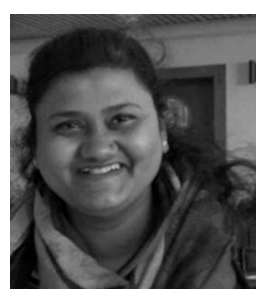

Ritu Srivastava, representing Jadeite Solutions, has over 14 years of experience in the development sector specifically focusing on the ICT domain, using digital technology towards sustainable development of underprivileged communities/marginalised sections of society. Her research interest lies in areas of broadband policies, gender and access, gender and internet governance, violence against women, open spectrum policies and community development. Ms Ritu holds a masters' degree in Electronics \& Telecommunication.

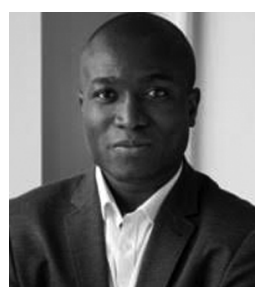

Georges Vivien Houngbonon is an Economist, specialised in digital technologies. He uses analytical methods to investigate the drivers of digital connectivity and its impact on economic and social outcomes.

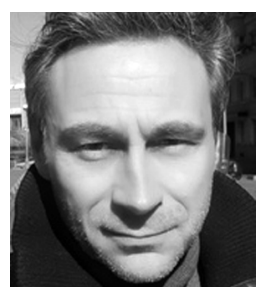

Erwan Le Quentrec holds a PhD in Economics from the University of Burgundy and is a manager in the Sociology and Economics of Networks and Services (SENSE) Department of Orange Labs. He is an expert in the uses related to ICTs, mobilising Digital Traces and Quali-Quantitative Methods. His activity aims to structure, implement and evaluate experiments in the field of mobile technology and coordinates collaborative innovation for Africa.

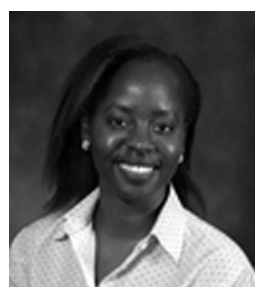

Josephine Miliza is a digital rights advocate focusing on affordable and meaningful access in Africa. She has a background in network engineering and is currently pursuing a master's in Information Technology at Deakin University Melbourne, Australia. She is the Africa regional coordinator for the Association of Progressive Communications Local access networks project and co-founder of the TunapandaNET community network. She is a champion of bottom-up sustainable connectivity models and creative approaches to an enabling environment that fosters entrepreneurship and innovation especially for youth and women in Africa.

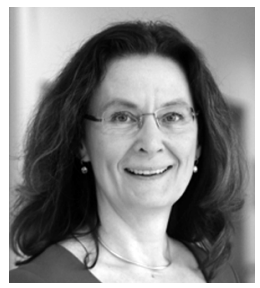

Andrea S. Winkler, MD, Dr. med., PhD, is a specialist neurologist, a senior researcher and the codirector of the Centre for Global Health at the Technical University of Munich. She is also the director of the Centre for Global Health at the University of Oslo, where she holds a full professorship in Global Health. Prof. Winkler has 18 years of experience with both clinical work and research in countries of sub-Saharan Africa. Her special interest lies with poverty-related neglected diseases of the infectious as well as non-infectious nature, global neurology/mental health and global digital health. She chairs the Lancet One Health Commission (together with Dr John Amuasi, KCCR, Ghana). 


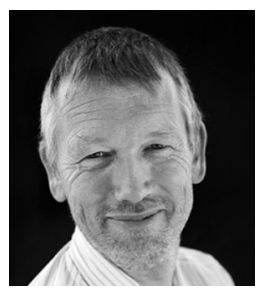

Josef Noll is Professor at the University of Oslo and Secretary-General at the Basic Internet Foundation. He has identified the digital divide as one of the big societal challenges. Through the Foundation he promotes "Internet Lite for All," the free access to information for everyone. Prof. Noll is project leader of the "Non-Discriminating Access for Digital Inclusion" project and the "Security for loT for Smart Grids" project. He is also involved in several Digital Health projects. Besides his academic background, he has worked for SIEMENS (DE), European Space Agency (NL) and Telenor (NO). 